\title{
Вариативность мировоззренческих формул в географии
}

\author{
НОВИКОВ А.Н. ${ }^{1}$, НОВИКОВА М.С. ${ }^{2}$ \\ ${ }^{1}$ Федеральное государственное бюджетное образовательное учреждение высшего образования \\ «Забайкальский государственный университет», Чита \\ ${ }^{2}$ Муниципальное бюджетное учреждение дополнительного образования «Детский \\ оздоровительно-образовательный центр детско-юношеского туризма и краеведения», Чита \\ geonov77@mail.ru
}

\begin{abstract}
Аннотация. География - мировоззренческая наука, вопрос восприятия географической реальности для нее ключевой. Использование мировоззренческих формул в курсе обучения географии определяет не только дальнейшее восприятие людьми по жизни географических явлений, процессов и объектов, но и ход развития географической науки.

В качестве метода исследования выступает диалектика, законы которой срабатывают в виде мировоззренческих формул.

Авторы рассматривают следующие формулы: дихотомию (двойственность), трихотомию (тройственность), четверичность (кватерность). Интерес вызывает работа мировоззренческих формул, которая выражается в разложении единого содержания на части (анализ) с его последующим соединением (синтез) в целое на межтематических, внутриэтапных, межэтапных уровнях.

Если вести речь в отношении курса обучения географии, то его структуру можно рассмотреть с позиции всех мировоззренческих формул. Дихотомия - это дополнительность естественной и общественной географии, которые на различных уровнях дополняют друг друга. Трихотомия позиционной, отраслевой и районной географии наблюдается как в естественной, так и в общественной географии. Существующая четырехэтапная структура географического образования - это оптимальное технологическое решение в формате четверичности, которое обобщает все другие мировоззренческие формулы и дает возможность их вариативному применению.

Восприятие географических объектов, процессов и явлений в формате мировоззренческих формул в системе географического образования сведено к дихотомии. Внедрение остальных формул остается главной задачей, которую необходимо решать на уровне высшего образования.

Показано, что в школьном географическом образовании проблема формирования восприятия не проявляется четко и поэтому не осознается. Проблемы начинают проявляться на межэтапном уровне.

Доказано, что в переходе с уровня на уровень возрастает самостоятельность географического мышления и удаление от стереотипов, возрастает эвристический потенциал за счет сочетания формул, которое дает вариативность отражения географической реальности.
\end{abstract}

Ключевые слова: диалектика, дихотомия, мировоззрение, трихотомия, четверичность.

\section{Variability of worldview formulas in geography}

\author{
NOVIKOV A.N. ${ }^{1}$, NOVIKOVA M.S. ${ }^{2}$ \\ ${ }^{1}$ Transbaikal State University, Chita \\ ${ }^{2}$ Children's Health and Educational Center for Children and Youth Tourism and Local Lore, Chita \\ geonov77@mail.ru
}

Abstract. Geography is a worldview science, the question of the perception of geographical reality is a key one for it. The use of worldview formulas in a geography course determines not only the further perception of geographical phenomena, processes and objects by people, but also determines the course of development of geographical science. The structure of a geography course in Russian high school that has been formed over decades consists of four stages. 
At the university, the training system for future geography teachers consists of the same stages, however, this is not just an in-depth repetition of the school curriculum, it is a completely new, higher level of geographical education. Both at the school and university levels, changes occur on the scale of topics and sections of individual stages, but the stages remain unchanged. The inter-stage level is the limit; its awareness does not fall into the field of reflection of teachers and methodologists. There are no scientific papers on its analysis.

The research method is dialectics, the laws of which work in the form of worldview formulas.

The authors consider the following formulas: dichotomy (duality), trichotomy (triplicity), quaternary (quaternity). Of interest is the work of worldview formulas, which is expressed in the decomposition of a single content into parts (analysis) with its subsequent combination (synthesis) into a whole at inter-topic, intra-stage, inter-stage levels.

With regard to the course of study of geography, its structure can be considered from the position of all worldview formulas. A dichotomy is the complementarity of natural and social geography, which complement each other at various levels. A trichotomy of positional, sectoral, and regional geography is observed in both natural and social geography. The existing four-stage structure of geographical education is an optimal technological solution in the quadruple format, which summarizes all other worldview formulas and makes it possible to use them variably.

The perception of geographical objects, processes and phenomena in the format of worldview formulas in the system of geographical education is reduced to a dichotomy. The introduction of the remaining formulas remains the main task that must be solved at the level of higher education.

It is shown that in school geographical education the problem of perception formation does not manifest itself clearly and therefore is not recognized. Problems begin to manifest at the inter-stage level.

Mastering worldview formulas is a matter of reflecting geographical reality. It is proved that in the transition from level to level, the independence of geographical thinking and distance from stereotypes increases, the heuristic potential increases due to the combination of formulas, which gives variability of the reflection of geographical reality.

Keywords: dialectics, dichotomy, worldview, trichotomy, quaternary.

\section{Введение}

География - мировоззренческая наука, вопрос восприятия географической реальности для нее ключевой. Использование мировоззренческих формул в курсе обучения географии определяет не только дальнейшее восприятие людьми по жизни географических явлений, процессов и объектов, но и ход развития географической науки. На каких мировоззренческих формулах воспитывался будущий ученый? Этот вопрос является принципиальным.

В большинстве своем академические ученые, как показывает опыт личных бесед одного из авторов (А.Н. Новиков), не интересуются школьным курсом географии. С университетским курсом знакомы только те ученые, которые занимаются преподавательской деятельностью. Отметим, что многие преподаватели не интересуются учебным планом и не владеют общей структурой географического образования кафедры, на которой осуществляют преподавательскую деятельность. А в программах географических конференций нет секций по проблемам преподавания географии в высшей и средней школе. В географии появляется все больше кандидатов и докторов педагогических наук, которые занимаются изучением проблем преподавания географии, но не занимаются собственно географией, т. е. не проводят географические исследования. В результате дистанция между географическим образованием и географической наукой увеличивается.

Сложившаяся за десятилетия структура курса обучения географии в российской средней школе известна и состоит из четырех этапов: первый - начальный, который дает представление об оболочках Земли, основах топографии и картографии (6 класс); второй этап - это знакомство с географией материков и океанов (7 класс); особенность третьего этапа в том, что в отличие от остальных он двухгодичный (8-9 классы) и работает на уровне страны - России, формируя представления о ее физической и социально-экономической географии; четвертый этап финальный - это изучение экономической и социальной географии мира (10 класс).

В университете система обучения будущих учителей географии состоит из тех же самых этапов, однако это не просто углубленное повторение школьной программы, это совершенно новый, более высокий уровень географического образования. Такая схема 
воплощает диалектический закон отрицания отрицания, демонстрируя спиралевидность развития географического образования с его преемственностью на различных уровнях.

Как на школьном, так и на университетском уровне изменения происходят в масштабе тем и разделов отдельных этапов, но этапы остаются неизменными. Возникает резонный вопрос о целесообразности такой традиционности в эпоху инновационных устремлений. В чем секрет такого постоянства межэтапного уровня?

Межэтапный уровень является предельным, его осознание не попадает в область рефлексии педагогов и методистов. Отсутствуют и научные труды по его анализу.

В педагогической науке, занимающейся теорией и методикой обучения географии, устремления исследователей чаще направлены на конкретные проблемы обучения в формате отдельных тем, разделов или классов. В рамках данного исследования авторы ставят цель - показать магистральную линию дополнительности мировоззренческих формул, которые логически сменяют друг друга на внутриэтапных и межэтапных уровнях. Проблема, которая выражается пословицей «За деревьями не видеть леса», характерна для современной теории и методики обучения географии.

Четырехэтапное географическое образование, реализующееся как на школьной, так и на университетской ступени - это генеральная стратегия. Разработки на уровне годовых циклов, разделов и тем выступают как тактические действия.

Цель статьи - выявить вариативность работы мировоззренческих формул при анализе структуры географического образования.

В качестве задач авторы ставят следующие:

- рассмотреть структуру географического образования с позиций мировоззренческих формул;

- выявить уровни повышения сложности применения мировоззренческих формул.

\section{Материалы и методы}

В качестве метода исследования выступает диалектика, законы которой срабатывают в виде мировоззренческих формул.

Формулы либо явно проявляются в географическом образовании средней школы, либо имеют скрытый характер. Авторы рассматривают следующие формулы: дихотомию (двойственность), трихотомию (тройственность), четверичность (кватерность). Интерес вызывает работа мировоззренческих формул, которая выражается в разложении единого содержания на части (анализ) с его последующим соединением (синтез) в целое на межтематических, внутриэтапных, межэтапных уровнях.

Дихотомия в географии - это воплощение диалектического закона единства и борьбы противоположностей, а трихотомия - перехода количественных изменений в качественные (появление третьего начала от взаимодействия двух с последующим качественным преобразованием двоичности в троичность).

Отметим, что перечисленные мировоззренческие формулы не противоречат, а дополняют друг друга, расширяя формат восприятия. Конечно, они имеют очень древнюю историю и первоначально вытекают из религиозных воззрений: дихотомия из идеалистической диалектики; трихотомия из христианства (учение о Святой Троице); четверичность из буддизма (четыре пути самосовершенствования) и христианства (четыре Евангелия).

Авторы статьи имеют опыт реализации трихотомии как мировоззренческой формулы в географических исследованиях [1-3].

Отметим, что современный этап отличается большим разнообразием в восприятии географии студентами и учителями, что связано со свободой вероисповедания. В советский период доминировала материалистическая диалектика, которая насаждала двойственное восприятие мира. 
Двойственное восприятие географической реальности выступает в качестве главного метода и в постсоветский период. Отметим концепцию континентально-океанической дихотомии Л.А. Безрукова [4] и концепцию поляризованной биосферы Б.Б. Родомана [5].

Указанные мировоззренческие формулы хорошо проработаны современной философией и логикой. Авторов интересует исключительно их конструктивный характер, освобожденный от религиозного и мистического подтекста.

\section{Результаты и их обсуждение}

\section{Структура географического образования с позиций мировоззренческих формул}

Проблема воспитания восприятия наиболее проработана в разделах музыкального и художественного образования, где она проявляется наиболее явно и поэтому отлично осознается. Авторам как университетским преподавателям приходилось с этой проблемой встречаться. В течение нескольких лет, организуя выезды на Дальнюю комплексную практику со студентами Забайкальского государственного университета в город Иркутск и Иркутскую область наряду с посещением промышленных предприятий читинскими студентами осуществлялись посещения музеев. В Художественном музее при знакомстве с картинами, написанными маслом, авторы статьи обращали внимание, что студенты не имеют навыка восприятиях таких произведений. Они начинают их внимательно рассматривать, приближаясь очень близко, видят только цветные мазки, не воспринимая, что же изображено на картине. Приходилось объяснять, что не нужно всматриваться в детали на близком расстоянии, а сделать шаг назад и постараться включить в поле зрения всю картину целиком. Приходилось таким образом работать над восприятием студентами художественного произведения.

Общаясь с педагогами музыкальной школы, авторы часто слышали их выражение: «Музыка не в нотах, она где-то между ними». Так наставники объясняют начинающим музыкантам, что выучить ноты - это еще не означает выучить произведение. Необходимо сочетание ритмичности и плавности исполнения, которые выражают целостность музыкальной композиции.

В географии для познания планетарных процессов и структур недостаточно выучить всю региональную географию. Необходимо целостное восприятие Земли как планеты.

В школьном географическом образовании подобная проблема не проявляется так четко и поэтому не осознается, нуждаясь в постановке и обозначении степени остроты на различных уровнях: внутритематическом (на уровне недели обучения), межтематическом (на уровне четверти учебного года), внутриклассовом (на уровне годовой школьной ступени) и наиболее масштабном - межэтапном.

Острота проблемы нарастает по мере перехода с одного уровня на другой - более высокий уровень.

На внутритематическом уровне эта проблема практически не проявляется, так как педагоги уделяют большое внимание методике преподавания отдельных тем в географии на уровне научных работ, да и технологии преподавания отдельных тем наиболее проработаны. Проблема может возникнуть из-за индивидуальных особенностей ученика - нежелания учиться или особенностей психического развития.

Проблемы начинаются на межтематическом уровне, когда включается фактор времени, т. е. синтез происходит гораздо позже анализа. Обучающиеся успевают забыть часть материала, а механизмы комплексирования в последние два десятилетия сильно ослабли в отечественной школьной географии. Эти механизмы базировались на серьезных научных концепциях: природно-территориального комплекса с геохимическими циклами, территориально-производственного комплекса с энергопроизводственными циклами. Проблема возникает из-за научной редукции (упрощения) содержания школьной географии. В по- 
следние два десятилетия решалась проблема перегруженности обучающихся научными терминами и некоторые ключевые для географии понятия исчезли из курса обучения, а именно они выполняли функцию обеспечения формы географического синтеза. А синтез без формы невозможен. Кроме того, что бесформенная региональная география не осознается ребенком и не оставляет целостных географических образов стран и регионов, она не дает ему почувствовать противопоставление «отраслевая география - районная география», не дает осознать взаимодействие между ними по принципу «отраслевой анализ региональный синтез». Именно здесь «прерывается цепь» целостного географического образования. При этом ребенок теряет восприятие географической дихотомии.

Межтематический уровень в пределах одного этапа назовем внутриэтапным. На внутриэтапных уровнях должна происходить активная работа мировоззренческих формул, но если связь между темами потеряна, то этого не происходит. Это самый главный барьер на пути формирования мировоззрения, который делает уже внутриклассовый уровень географического образования фрагментарным, теряющим целостность.

На внутриэтапном уровне в советский период устанавливалась формула географической дихотомии, которая играла роль модели научного объяснения.

На первом - начальном этапе, который дает представление об оболочках Земли, это противоречия, являющиеся причиной развития этих оболочек. Например, одно из ключевых понятий темы «Литосфера» - «рельеф» предстает в курсе изучения географии как результат борьбы эндогенных и экзогенных сил. А в изучении темы «Атмосфера» движения воздушных масс рассматриваются как результат борьбы барических максимумов и барических минимумов. Изучение топографии и картографии уже само по себе есть деление всех геоизображений на два типа по масштабу.

В названии второго этапа - «География материков и океанов» - тоже заложена дихотомия, которая подчеркивает деление Земли на территории и акватории.

Третий этап раскрывает школьникам двойственную сущность географической науки в делении ее на естественную и общественную (гуманитарную) части при изучении России.

Четвертый этап дает представление о бинарных оппозициях: «развитые страны - развивающиеся страны»; «специализация - кооперация»; «глобальное - региональное».

По задумке основателей материалистического географического образования школьник, завершая среднее образование, должен быть подготовлен к осознанию материалистической диалектики в университете, будучи воспитанным на мировоззренческой формуле восприятия двойственности всего сущего. В университете количество школьных знаний должно перейти в качество - осознание. Восприятие уже университетской программы должно идти диалектически осознанно.

Часть студентов действительно проходят через эту двоичную схему. Более того, некоторые из них в дальнейшем «проносят» эту формулу через кандидатские и докторские исследования.

Дихотомия является главной мировоззренческой формулой в географии или главной формой научного объяснения. Однако параллельно с дихотомической формулой «включается» трихотомическая, а в отдельных случаях присутствует и кватерная (четверичная).

Например, в физической географии все территории (регионы и страны) изучаются отраслевым (аналитическим) путем, будь то география почв или география машиностроения, а уже после районным (синтетическим). Введение районного пути изучения географии Н.Н. Баранским [6] в школьный и вузовский курсы можно назвать революционным в методике преподавания предмета. Однако уже во внедренной Баранским двойственной (дихотомичной) формуле можно разглядеть переход к тройственной (трихотомичной) формуле. Заключенная в отраслевую часть тема «Географическое положение» по характеру своего содержания не вписывается в нее, она не дает, как другие темы, отраслевого покомпонентного анализа, а выявляет позицию территории. С усилением глобализации эта тема приобретает черты самостоятельности и требует особого внимания при изучении экономико-географического, геополитического и эколого-географического видов по- 
ложения. По сути, появляется новая формула трихотомии, которая приобретает характер завершенной географической трилогии.

Четверичность, как и троичность, тоже присутствует в географическом образовании, но еще не осознана. Идеи о четверичном подходе в психологии были разработаны Карлом Густавом Юнгом [7].

Рассмотрим два варианта проявления четверичности в географии, выразив их следующими сочетаниями частей: «2+2» и «3+1».

Первый вариант - это сочетание двух пар, каждая из которых является бинарной оппозицией. Например, времена года как две оппозиции: одна оппозиция основных сезонов («зима - лето») и одна оппозиция переходных («весна - осень»). Еще один пример, «север - юг» и «запад - восток». В данном случае возникает мандалический образ горизонта, а географическая карта воспринимается как четверица (тетрактида).

Сочетание «3+1»- это когда одна часть качественно отличается от трех предыдущих. Это может быть тринитарная формула, дополненная четвертым началом. Например, территориальные структуры - это триада точечных, линейных и площадных элементов, которые дополняются четвертым началом - временем. Триада, развиваясь во времени, становится четверицей.

Еще один пример - это четверица физико-географической оболочки, где одна геосфеpa - биосфера качественно отличается от трех других (атмосферы, гидросферы и литосферы).

Одна из главных задач теоретической географии - осознание различных мировоззренческих формул и их сознательное применение в будущем для приращения нового знания и разнообразия научного объяснения. В противном случае мировоззренческая роль географии будет заужена до бинарных оппозиций, что мы наблюдали в советский этап развития науки.

Как уже отмечалось, курс обучения географии в школе состоит из 4 этапов, его тоже можно воспринимать как географическую тетрактиду, соотношение четвертей «3+1». Отметим, что первый, второй и четвертый этапы относятся к глобальной географии, а третий этап особенный. Он является страноведческим и посвящен географии России.

Межэтапный уровень - предельный в географическом образовании. Проблема соотношения континуальности и дискретности изучаемого материала здесь самая острая. Именно здесь должна проявиться социальная роль теоретической географии, которая призвана не только обеспечить развитие географической науки, но и снабдить географическое образование моделями формирования географических образов отдельных стран и регионов и целостной географической картины мира. Предложить что-то новое взамен территориальных комплексов.

В современном информационном обществе географические компетенции благодаря геоинформационным технологиям переходят в ранг общекультурных. Все больше людей начинают использовать через свои смартфоны функцию «геоданные», определять свое местоположение и прокладывать маршруты передвижения.

Географическое восприятие реальности у современного человека существенно изменяется из-за развития связи и транспортной мобильности. Количество географической информации о территориях и акваториях увеличивается. Возникает проблема географического восприятия, которая заключается в том, что человек в условиях избытка информации перестает перерабатывать ее: анализировать, выбирать главное, сравнивать и обобщать. Человек перестает удивляться географическим переменам, когда пересекает границы природных зон. Естественно, что выучить всю инвентаризационную (энциклопедическую) географию во внутритематических форматах невозможно. Такое устремление было в школах еще 100 лет назад. География была одним из нелюбимых предметов детей, так как сводилась к изучению у географической карты нанесенных на нее объектов. Однако современные школьники с каждым годом знают энциклопедическую географию все хуже, полагаясь на электронные носители. Мозг людей часть своих функций по запоминанию переносит на «внешние носители». Проблема отбора материалов для запомина- 
ния стоит очень остро в географии. Но даже тщательно отобранный материал необходимо запоминать в определенной системе, придавая ему четкие формы на межтематических, внутриэтапных, межэтапных уровнях. Потребность в формах синтеза географической информации возрастает. Авторы не предлагают вернуть в курс школьной географии отмененные понятия (территориально-производственный комплекс и природно-территориальный комплекс), можно ввести более современные: возможно, географические кластеры.

\section{Уровни повышения сложности применения мировоззренческих формул}

Современная система географического образования в средней школе и на географических кафедрах в университетах - это продукт длительной эволюции. Основная функция этой системы - вооружить человека мировоззренческими формулами, которые в будущем позволят ему адекватно отражать географическую реальность. Проблема готовности обучающимися пользоваться этими формулами самая острая: часть воспитанников, заучив ряды примеров проявления этих формул, не выходят за их пределы; другая часть людей использует эти формулы как «мировоззренческое лекало», находя в каждой географической ситуации свою единственную формулу (чаще дихотомию). В последнем случае мы наблюдаем стереотипное мышление. По своей сути, географическое образование порогового уровня - это формирование ряда примеров у обучаемого, которыми он оперирует. Следующий уровень - стандартный, который отличается вооружением «мировоззренческим лекалом». Наивысший - эталонный уровень, представители которого владеют умением применения нескольких мировоззренческих формул для объяснения одной и той же географической ситуации. Именно в вариативности проявляется гибкость ума, как необходимое качество мышления исследователя.

В современной педагогике зарубежными авторами Кэролайн Бейли (Caroline Baillie), Джон А. Боуден (John A. Bowden), Ян Х. Ф. Мейер (Jan H. F. Meyer) активно внедряется концепция Интегрированной теоретической структуры пороговых возможностей (Тhe Threshold Capability Integrated Theoretical Framework) [8], которая выступает в качестве основы для разработки учебных программ университетов, направленных на развитие способности выпускников справляться с ранее невиданными ситуациями в их профессиональной, социальной и личной жизни.

В переходе с уровня на уровень возрастает самостоятельность географического мышления и удаление от стереотипов. По своей сути первый, пороговый, уровень не является географическим мышлением как таковым, а демонстрирует лишь возможность человеческой памяти вспомнить подходящий заученный пример бинарной оппозиции. Возможность объяснения в географии в этом случае ограничивается тем, вспомнит человек пример или нет. Следующий, стандартный, уровень предполагает демонстрацию самостоятельности мышления, т. е. умение увидеть диалектическое противоречие в каждой конкретной ситуации и сформулировать его в виде бинарной оппозиции. Выходящий на этот уровень человек отправляется в «свободное плавание», он способен самостоятельно проводить анализ в географии.

Эталонный уровень можно идентифицировать как «высший пилотаж» географической мысли. Выход на этот уровень наталкивается на барьеры, которые закладывает сама система образования, а именно - акцент на бинарных оппозициях. Способность за бинарными оппозициями - диадами видеть триады и тетрады свидетельствует о вариативности комплексирования, на которую способен исследователь.

\section{Заключение и выводы}

Формула дихотомии перестала работать в виде противопоставления «отраслевая география - районная география», взаимодействие в этой бинарной оппозиции строилось по принципу «отраслевой анализ - региональный синтез». Из разделов районной 
географии исчезли механизмы и формы синтеза. Произошла утрата целесообразности изучения районной географии. Новых форм синтеза в постсоветское время на вооружение школьной географии принято не было. В университетском курсе, который был направлен на осознание диалектических знаний школьного курса и их развитие, невозможно провести рефлексию, так как основы географических знаний у абитуриентов бесформенные. Формула трихотомии не заменила дихотомию, так как имеет скрытый характер. Формула четверичности нуждается в осознании на теоретико-географическом уровне.

Владение мировоззренческими формулами - это вопрос отражения географической реальности. В переходе с уровня на уровень возрастает самостоятельность географического мышления и удаление от стереотипов, возрастает эвристический потенциал за счет сочетания формул, которое дает вариативность отражения географической реальности. Существующая четырехэтапная структура - это оптимальное технологическое решение, так как она отражает вариативность применения мировоззренческих формул. Восприятие географических объектов, процессов и явлений в формате мировоззренческих формул в системе географического образования сведено к дихотомии. Внедрение остальных формул остается главной задачей, которую необходимо решать на уровне высшего образования.

\section{Литература}

1. Baklanov P.Ya., Novikov A.N., Ptitsyn A.B. Structural and Geographical Analysis of Cross Border Three Member Areas // Doklady Earth Sciences. 2016. Vol. 468, pt 1. P. 493-495. DOI: 10.7868/S0869565216130132

2. Kozyreva K.S., Novikov A.N., Novikova M.S. The asymmetry of tourist images for the international crossborderthree-membered region of the eastern borders junction of Russia, Mongolia and China // J. Fundam. Appl. Sci. // 2017. 9(2S). P. 1614-1637. - http://dx.doi.org/10.4314/jfas.v9i2s.865

3. Бакланов П.Я., Новиков А.Н., Новикова М.С. Влияние трансграничности на территориальные структуры Приморского края России и сопредельных территорий // Ученые записки Казанского университета. Серия: Естественные науки. 2018. Т. 160, № 1. С. 162-177.

4. Безруков Л.А. Континентально-океаническая дихотомия в международном и региональном развитии. Новосибирск: Гео, 2008. 369 с.

5. Родоман Б.Б. Поляризованная биосфера. Смоленск: Ойкумена, 2002. 336 с.

6. Баранский Н.Н. Становление советской экономической географии: избранные труды. М.: Мысль, 1980. $287 \mathrm{c}$.

7. Юнг К.Г. Архетип и символ. М.: Ренессанс, 1991. 300 с.

8. Baillie C., Bowden J., Meyer J. Threshold capabilities: threshold concepts and knowledge capability linked through variation theory // Higher Education. 2013. February. Vol. 65, iss. 2. P 227-246. - https://doi.org/10.1007/ s10734-012-9540-5

\section{References}

1. Baklanov, P.Ya., Novikov, A.N., Ptitsyn, A.B. Structural and Geographical Analysis of Cross Border Three Member Areas. Doklady Earth Sciences. 2016, 468, pt 1, p. 493-495. DOI: 10.7868/S0869565216130132.

2. Kozyreva, K.S., Novikov, A.N., Novikova, M.S. The asymmetry of tourist images for the international crossborderthree-membered region of the eastern borders junction of Russia, Mongolia and China. J. Fundam. Appl. Sci., 2017, 9(2S), 1614-1637. - http://dx.doi.org/10.4314/jfas.v9i2s.865.

3. Baklanov, P.Ya., Novikov, A.N., Novikova, M.S. The effect of cross-border on the territorial structures of the Primorsky Territory of Russia and adjacent territories. Scientific notes of Kazan University. Series: Natural Sciences. 2018. Vol. 160, No. 1. P. 162-177. (In Russian)

4. Bezrukov, L.A. Continental-oceanic dichotomy in international and regional development. Novosibirsk: Geo, 2008. 369 p. (In Russian)

5. Rodoman, B.B. Polarized Biosphere. Smolensk: Oykumena, 2002, 336 p. (In Russian)

6. Baransky, N.N. The Formation of Soviet Economic Geography: Selected Works. Moscow: Mysl, 1980. 287 p. (In Russian)

7. Jung, K.G. Archetype and symbol. Moscow: Renaissance, 1991. 300 p.

8. Baillie, C., Bowden, J., Meyer, J. Threshold capabilities: threshold concepts and knowledge capability linked through variation theory. Higher Education, February 2013, Vol. 65, Issue 2, p. 227-246. - https://doi.org/10.1007/ s10734-012-9540-5. 